\title{
Study of Wangkuai-Xidayang Reservoir Comprehensive Management Project
}

\author{
Changying SHI \\ College of Water Conservancy and Electric Power \\ Heilongjiang University \\ Harbin,P.R. China \\ shicy2004@126.com
}

\author{
Lijuan WANG \\ Adult Education College \\ Hebei University of Engineering \\ Handan,P.R. China \\ wlj3123595@126.com
}

\begin{abstract}
After implementing the comprehensive management project of wangkuai-Xidayang reservoir, water supplementing Baiyangdian Lake from Wangkuai Reservoir will pass through the rivers in Baoding urban area, providing water for environment in Baoding Municipality. It can counteract heat-island effect and beautify sight of city, improve quality of dwellers, form a green passage conveying water and play an important part in ecological construction in Baoding Municipality. In a word, constructing the comprehensive management project of Wangkuai-Xidayang reservoir is benefit for present and the future, the people and the country, and is imperative under the situation.
\end{abstract}

Keywords-reservoir; comprehensive management project; study

\section{OVERVIEW}

Baiyangdian Lake in Hebei Province is the largest remaining semi-closed freshwater body in the northern part of the PRC [1]. The Lake lies in the middle reaches of the Daqinghe River Basin and ultimately discharges into the Bohai Gulf, Yellow Sea. Much of the upstream catchment totalling $31500 \mathrm{~km}^{2}$ lies within the 22 counties and urban districts that come under the jurisdiction of Baoding Municipality and all of the lake body is located in Anxin and Xiong Counties of Baoding[2]. The lake has a surface area of $366 \mathrm{~km}^{2}$ and comprises a series of natural low-lying depressions and reed marshes. While nine rivers and/or channels flow into Baiyangdian Lake, only two have regular but decreasing flows, namely, Fuhe and Juma rivers[3].

The Wangkuai-Xidayang Reservoir Connection Project passes across several counties and cities such as Quyang county, Tangxian county, Shunping county, Baoding Municipality and Qingyuan county, and refills water from Wangkuai Reservoir located in Shahe watershed and Xidayang Reservoir located in Tanghe watershed to Baiyangdian Lake and Yimuquan groundwater water source zone, and the transferred water comes mainly from Wangkuai Reservoir. The water of Wangkuai Reservoir is firstly transferred to Xidayang Reservoir, then flows along the main canal in Tanghe irrigation district, and arrives at the Weicun Village Aqueduct[4]. At Weicun Village aqueduct, the transferred water from Xidayang reservoir is divided into two parts, i.e. South Line and North Line. The routine of South Line is: Weicun Village aqueduct $\rightarrow$ Weicun Village recession sluice $\rightarrow$ Qunihe River $\rightarrow$ Jiehe River $\rightarrow$ Baicaogou water diversion junction at Fangshun Bridge in Shunping County $\rightarrow$ Baicaogou Valley $\rightarrow$ the rivers passing through the urban area of Baoding Municipality (such as Xihuandi River, Yimuquan River, Houhe River and Baoding Municipality moat) $\rightarrow$ Fuhe River $\rightarrow$ Baiyangdian Lake. The routine of South Line is: Weicun Village aqueduct $\rightarrow$ main canal in Tanghe irrigation district $\rightarrow a$ newly-constructed or extended canal $\rightarrow$ Yimuquan groundwater recharge zone.

The primary task of the project is to form a green channel of refilling water from Wangkuai Reservoir to Baiyangdian Lake, to supply more water to the Baiyangdian Lake, to reduce the situation of wetland shrinkage in Baiyangdian Lake, to improve the ecological environment in the lake area, and to prevent Baiyangdian Lake from drying up[5]. Other tasks of the project are: to improve the water supply guarantee rate of Xidayang Reservoir, to provide spare water resources for Baoding Municipality and further enhance the water supply security of Baoding Municipality, and to reduce effectively the effects of urban heat island, and to improve the living quality of the urban residents and improve the urban water environment of Baoding Municipality, and opportunely refill water to the groundwater at Yimuquan aquifer zone and relieve the problem of worsening hydro-geological environment due to the excessive overdraft of groundwater for a long time[6].

The total length of the water transfer course between Wangkuai Reservoir and Baiyangdian Lake is about 140.0 $\mathrm{km}$, while that between Weicun Village aqueduct and Nanwuhou Yimuquan aquifer zone is about $20.75 \mathrm{~m}$. The general layout map of Wangkuai-Xidayang Reservoir Connection Project is shown in the following figure. 


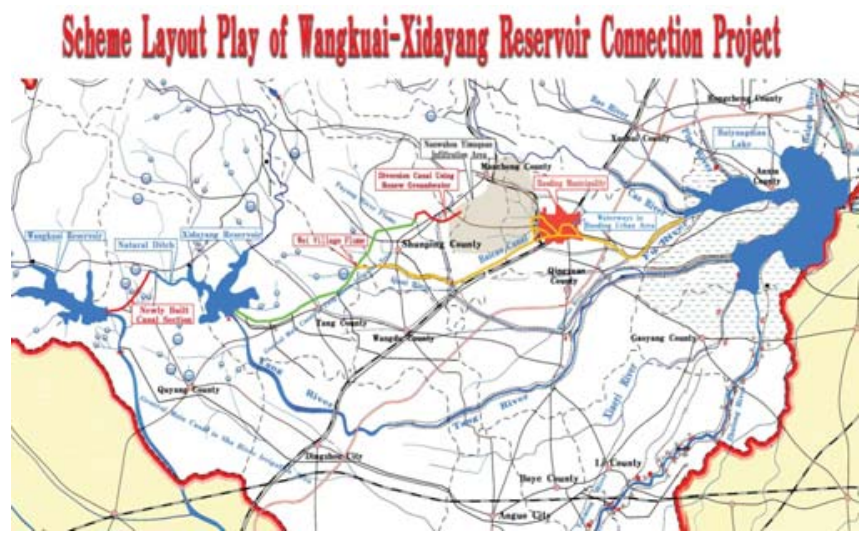

Figure 1. Scheme Layout Play of Wangkuai-Xidayang Reservoir Comprehensive Management Project.

\section{NeCESSITY FOR THE PROJECT}

\section{A. The Present Situation of Baiyangdian Lake}

Baiyangdian Lake is situated at the triangle centre of Beijing, Tianjin and Shijiazhuang. It is administrated by five different counties including Anxin County, Rongcheng County, Xiong County and Gaoyang County of Baoding Municipality as well as Renqiu County in Cangzhou City[7]. Baiyangdian Lake, covering an area of $366.0 \mathrm{~km}^{2}$, is composed of 143 small and big lakes and over 3,700 trenches. With a water level of less than $8.8 \mathrm{~m}$, almost $85.6 \%$ of the total lake water area is within the administrative scope of Anxin County. Baiyangdian Lake is a semi-closed type shallow plain lake, thus it possesses no multi-year regulating capacity. The water level of Baiyangdian Lake in normal years is about $7.3 \sim 8.5 \mathrm{~m}$. If the water level of Baiyangdian Lake is less than $6.5 \mathrm{~m}$, the corresponding total storage amount of the Lake is less than 52.0 million $\mathrm{m}^{3}$, and the corresponding water surface area is only $70.0 \mathrm{~km}^{2}$, and Baiyangdian Lake is considered as a drying up lake[8].

Baiyangdian Lake is the largest ecological wetland system in North China. In the past decades years, because of the effects of insufficient water source, unstable water level and water quality pollution as well as groundwater over-exploitation, etc, Baiyangdian Lake has been subjected to lake drying up and low water level for several times. As a result, the polluted water can not be diluted, and the wetland in Baiyangdian Lake begins to degrade and shrink, and the growth condition of hydrophytic plants such as reed is lost. In addition, large-area reed land becomes wetland meadow, and then turns into dry grassland. Especially, for water drainage or water diversion, ditches and canals and even embankment have been constructed randomly in the hinterland of wetland in Baiyangdian Lake, which accelerates the fragmentation and insularity of wetland, and reduces the self-purification ability of wetland greatly, and cuts off the natural relationship among wetland plants and the migration channels of fish species and other aquatic animals living in wetland[9]. As a result, the biologic species diversity of wetland in Baiyangdian Lake and the sustainable development of the local aquaculture industries have been threatened and influenced seriously.
There existing a certain water level is the key measure of improving and maintaining the ecological environment in Baiyangdian Lake[10]. For enhancing the protection of wetland in Baiyangdian Lake and preventing the Lake from drying up and maintaining the normal water level in navigation channel in the Lake, Baiyangdian Lake has been refilled emergently through water conservancy projects for several time in the past over twenty years. However, the possibility of Baiyangdian Lake drying up still exists because the long-term effective mechanism of refilling water to the Lake is deficient.

Baiy an gdian Lake D agu Water Level $\sim$ Cub age Curve

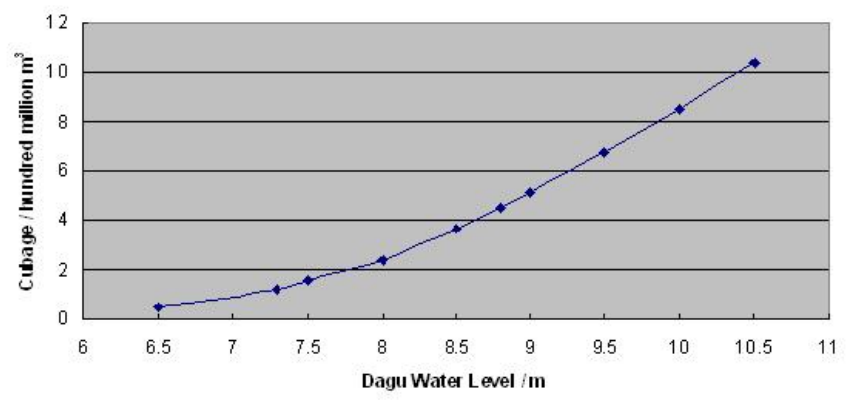

Figure 2. Baiyangdian Lake Dagu Water Level $\sim$ Cubage Curve.

Baiyangdian Lake Dagu W ater Level $\sim$ Area Curve

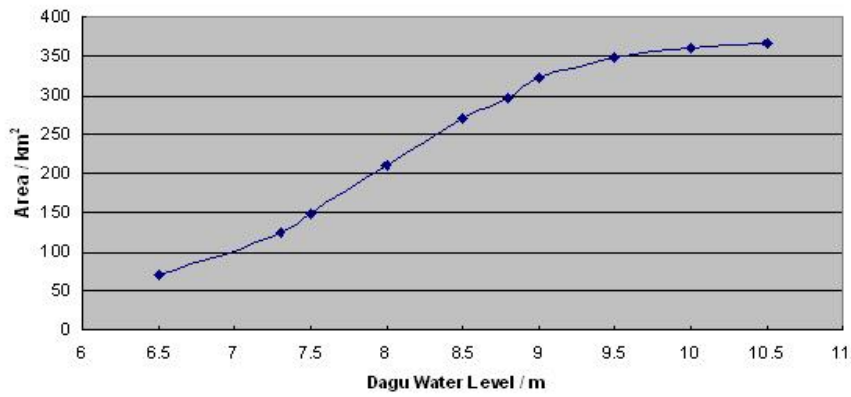

Figure 3. Baiyangdian Lake Dagu Water Level Area Curve

\section{B. The Regional Functions of Baiyangdian Lake}

Baiyangdian Lake is the only large perennial-flooded freshwater lake in North China Plain, whose main regional functions are as follows:

First, maintaining ecological balance and regulating local climate. After the long-term development and succession, the 16 large lakes in the plain regions in Hebei Province have totally dried up, while the special geography condition makes Baiyangdian Lake the only large plain lake and wetland in North China[11]. Baiyangdian Lake, nicknamed the kidney of North China, has played an important role in maintaining ecological balance in Hebei plains, and in protecting biological diversity and rare species resources. The annual mean water surface evaporation is about $1,369.0$ $\mathrm{mm}$. The total amount of water surface evaporation and lake water leakage of Baiyangdian Lake is nearly 0.3 billion $\mathrm{m}^{3}$, 
which could play an distinct role in improving the air temperature and humidity of North China and relieving dry climate and protecting groundwater resources. In addition, the effect of Baiyangdian Lake on the improvement of air temperature and humidity of Beijing and on the reduction of blown sand hazards is significant.

Second, retaining floods and protecting security of lower reaches. Baiyangdian Lake has been responsible for protecting the securities of Tianjin, and Jin-Hu railway, and people's lives and properties in the lower reaches for a long time. The construction of the large water control projects such as Zaolinzhuang project and Xingaifang project make Baiyangdian Lake a water conservancy basic facility with comprehensive function. Flood in Baiyangdian Lake discharges from Zaolinzhuang to western wharf controlling gate via new Zhaowang channel through Eastern Lake into the sea flowing across Haihe and Duliujianhe in Tianjin. During the extraordinary flood happened in 1963, Baiyangdian Lake stored and detained 3.8 billions $\mathrm{m}^{3}$ of flood, which protect the safety of passing through the flood period for Tianjin City and Jin-Hu railway. Now, with the acceleration of city construction, economical high-speed growth, the expansion of cities, as well as the increase of population density, the important infrastructures such as Jing-Jiu railway and Jin-Bao highway and North China oil field, make higher demands on the function of flood control of Baiyangdian Lake.

Third, enhancing economic function and developing the emerging tourism industry. Baiyangdian Lake is the traditional base of freshwater aquatic products of North China, and is one of the main supply bases of aquatic products of Beijing-Tianjin-Baoding-Langfang Area[12]. Because of the special beautiful scene, the famous and local special products and the traditional water town culture, Baiyangdian Lake is well-known all over the world and becomes a famous tourist scenic spot around Beijing. As a result, it has huge potential for developing tourism industry. The stable historical water environment and rich aquatic biology species make the material civilization and water town culture of Baiyangdian Lake. The flourish and decline of Baiyangdian Lake determined has very significant effect on the existence and development of people living in or around Baiyangdian Lake.

Finally, improving irrigation water supply. Baiyangdian Lake is the main water source of agricultural and industrial water supply of North China Oil Field and its surrounding area. With the rapid economic and social development of North China, North China has entered a period of serious water shortage. Most of the cities and towns in North China face the same serious problem of water shortage, where the groundwater is over-exploited and water environment becomes worsen and worsen. After the completion of the middle route of South-North Water Diversion Project, the functions of water supply and regulation capacities of Baiyangdian Lake will be enhanced, and the lake will become the important surface water source of
Beijing-Tianjin-Hebei Area. The mostly function of 28 locks and culverts distributing surrounding embankment is providing agricultureal water.

\section{The Existing Problems of Baiyangdian Lake}

Because of the influences of insufficient water resources and large scale human being economic activities, Baiyangdian Lake is degrading and shrinking gradually, and the lake water area is decreasing, and the water quality is getting polluted. According to the decision of the on-site conference on pollution control of Baiyangdian Lake, which was held in Baoding Municipality by State Council Environmental Protection Committee in1992, the Comprehensive Pollution Control Plan for Baiyangdian Lake was formulated and promulgated by the People's Government of Hebei Province. With several years' efforts, the tasks proposed in the Plan have been accomplished largely. In November 1998, the Comprehensive Pollution Control Program for Baiyangdian Lake received State-level approval. According to the Program, the water level in Baiyangdian Lake is $7.6 \mathrm{~m}$, and the lake areas with water qualities of Class III, IV, V, below V respectively accounts for $32 \%, 32 \%, 10 \%$ and $6 \%$. However, the implementation of the pollution control program has been intermittent; the problems of Baiyangdian Lake such as insufficient water resources and water pollution have persisted; and the environment system of Baiyangdian Lake is still very vulnerable. The existing main problems of Baiyangdian Lake are as follows:

First, serious scarcity of water resources and grave situation of drying up of the most rivers flowing into Baiyangdian Lake. Baiyangdian Lake is located in the water shortage regions in North China, with mean annual total water resources amount of 3.11 billion $\mathrm{m}^{3}$, and per capita water resources volume of less than $300 \mathrm{~m}^{3}$ which accounts for only $12.5 \%$ of that of national mean volume. Groundwater overexploitation is very serious, with annual over-exploited groundwater of $0.4 \sim 0.5$ billion $\mathrm{m}^{3}$, and the water level of local groundwater decline with a velocity of about $1.0 \mathrm{~m} / \mathrm{a}$. As a result, the area of local groundwater funnel is up to $2,160 \mathrm{~km}^{2}$. At present, only Juma River and $\mathrm{Fu}$ River among the 9 rivers flowing into Baiyangdian Lake have a certain amount of water entering Baiyangdian Lake in some seasons every year, while the other rivers belong to seasonal river and remain water cut-off for a long time except in flood season. Baiyangdian Lake is a semi-closed type shallow plain lake, thus possesses no multi-year regulating capacity. In addition, the seasonal distribution and the inter-annual variation of precipitation in the region are quite uneven. Abundant water must be abandoned in wet year or flood period every year, while the water inflow of Baiyangdian Lake cannot be ensured in dry year. Although Baiyangdian Lake has been refilled for several times in recent years, the possibility of Baiyangdian Lake drying up still exists because the long-term effective mechanism of refilling water to Baiyangdian Lake is deficient. 
Second, worsening water pollution and water eutrophication in Baiyangdian Lake. Among the rivers flowing into Baiyangdian Lake, except for the water of Juma River meet the water quality standard of Class III. Most of the waters with the inflow of Industrial and domestic sewage in other rivers have a water quality than inferior Class V. In addition, the main pollutants in the mentioned rivers include COD, N, P, and other nutrient substances. Because of the lack of precipitation runoff supply, some rivers are becoming pollutant-loaded rivers, and their ecological functions are diminishing. As a result, people's lives along the rivers have been affected seriously, and the rivers become the main pollution sources of pollution and eutrophication of the Baiyangdian Lake. In recent years, the water level in Baiyangdian Lake has been fluctuating around the critical level of drying up. As a result, the water quality of Baiyangdian Lake has been worsening. Now, only the water in the water area occupying about $10 \%$ of the total lake area reach the water quality standard of Class III, while that in the other water area only meet the water quality standard of Class V and even inferior Class V. The main pollutants in Baiyangdian Lake consist of COD, total phosphorus and total nitrogen, etc. And most of the water bodies in Baiyangdian Lake have been eutrophicated.

Finally, decline of ecological function and the frangible ecological system of Baiyangdian Lake. Baiyangdian Lake is a sort of natural resource, which was formed in the long course of natural and historical evolution, possesses the characteristics including naturalness, uniqueness, typicalness, ecological fragility, etc. In the past decades years, because of insufficient water source, unstable water level, water quality pollution, over-exploitation, etc, the aquatic organism have been destroyed fatally for several times, as a result, the ecological system of Baiyangdian Lake has been more and more fragile; and the ecological function of the lake has been degraded gradually. In addition, the living environment of wild animals in Baiyangdian Lake has also been worsening. Because the changes of ecological environment factors such as water quality and quantity, lead to the change of the species population structure, the natural fish resources in Baiyangdian Lake have been destroyed fatally, and a lot of valuable fish species have become extinct, and the existing fish species have become smaller.

\section{CONCLUSION}

To conclude, it is necessary and urgent to construct the Wangkuai-Xidayang Reservoir Comprehensive Management Project for rationally allocating surface water resources and alleviating the lack of water resources in Baiyangdian Lake, and controlling water pollution and ensuring the quality of water resources as well as realizing the sustainable utilization of water resources.

\section{REFERENCES}

[1] Dorigo M, Maniezzo V,Colorni A, The ant system: soptimization by a colony of cooperating agents. IEEE Transactions on systems, Man, and Cybernetics-Part B, Vol 26, pp.1-13, 1996.

[2] Dorigo M, Gambardella L M. Ant colony system: A cooperative learning approach to traveling salesman problem[J]. IEEE Trans Evolution Computation, Vol 1, pp.53-56, 1997.

[3] SHI Chang-ying,JIAN Xin-ping,LI Li-ying. Co-operation of Wangkuai Reservoir and Xidayang Reservoir.Journal of Engineering of Heilongjiang University, Vol 3, pp.7-10, 2012 (In Chinese).

[4] YUAN Jun-peng,YUAN Ji-dong,SHI Chang-ying. Study on Wangkuai-Xidayang Reservoirs of Inter-basin Water Transfer. South-to-North Water Transfers and Water Science \& Technology, Vol 5, pp.151-153, 2007 (In Chinese).

[5] JIAN Xin-ping. Study on the Connection of Wangkuai Reservoir and Xidayang Reservoir Based on System Dynamics[D]. Hebei University of Engineering,2009

[6] YUAN Jun-peng. Control and Decision, Vol 19, pp.1321-1326,1340, 2004 (In Chinese)

[7] Zongyong Zhang,Jing Sun,Jiahua Tan, Application of the Improved Ant Colony Algorithm. Journal of Shanghai Jiaotong University, Vol 33, pp.1564-1567, 2002 (In Chinese).

[8] Zhihan Wu, Experimental Method to Optimize Ant Colony System Parameters. Computer \& Digital Engineering, Vol 35, pp.49-51, 2007 (In Chinese).

[9] Yi Zhang,Yanchun Liang, Research of optimal selection on parameters of ant colony algorithm. Application Research of Computers, Vol 24, pp.70-71,83, 2007 (In Chinese).

[10] Yaping Tu,Ping Liu,Baoling Xie, Improvement for Parameters of Ant Algorithm. Journal of Chinese Computer Systems, Vol 28, pp.1985-1987, 2007 (In Chinese).

[11] Lingyan Jiang,Jun Zhang,Shunhong Zhong, Analysis of parameters in ant colony system. Computer Engineering and Applications, Vol 43, pp.31-36, 2007 (In Chinese).

[12] Zhiwei Ye,Zhaobao Zheng, Configuration of Parameters $\alpha, \beta, \rho$ in Ant Algorithm, Editorial Board of Geomatics and Information Science of Wuhan University, Vol 29, pp.597-601, 2004 (In Chinese). 